\title{
A tribute in memory of Prof. Leonardo Goldstein Jr.
}

\author{
Arai Augusta Bernardez Pecora ${ }^{1} \cdot$ Emerson dos Reis $^{2} \cdot$ Fábio Luís Fassani $^{3}$. \\ Francis H. R. França ${ }^{4} \cdot$ Jhon Jairo Ramirez Behainne $^{5}$. \\ Meuris Gurgel Carlos da Silva ${ }^{1}$ Waldir Bizzo ${ }^{1}$
}

Published online: 2 April 2015

(c) The Brazilian Society of Mechanical Sciences and Engineering 2015

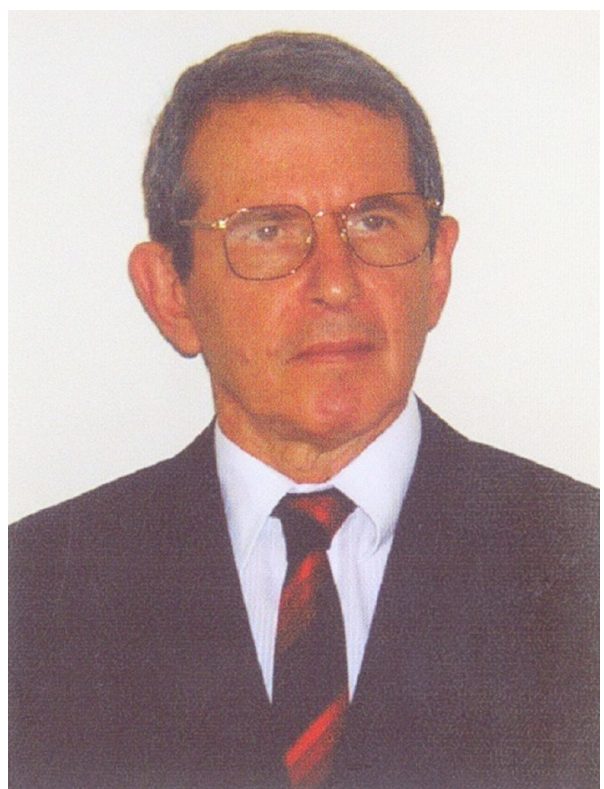

On January 28th, 2015, the Brazilian community of mechanical engineering and sciences was deeply saddened with the passing of Prof. Leonardo Goldstein Jr., Full

Francis H. R. França

frfranca@mecanica.ufrgs.br

1 State University of Campinas-UNICAMP, Campinas, SP, Brazil

2 Federal Institute of Education, Science and Technology-IFSP, São João da Boa Vista, SP, Brazil

3 National Civil Aviation Agency-ANAC, Campinas, SP, Brazil

4 Federal University of Rio Grande do Sul-UFRGS, Porto Alegre, RS, Brazil

5 Federal University of Technology-Paraná-UFTPR, Ponta Grossa, PR, Brazil
Professor at the State University of Campinas (UNICAMP). A role model of integrity and ethics, he was much admired by friends, colleagues and students for his remarkable contributions to teaching, research, engineering practice and academic administration. Most of all, he was an example of life for those who were fortunate to know him.

Leonardo was born in the city of São Paulo on August 10, 1943, the son of Maria de Lourdes and Leonardo Goldstein. He grew up with a sister, Rosa Maria, and two brothers, Paulo Jacques and Marcelo. Leonardo married Lucila in 1969, and had three children, André, Gustavo and Julia. A loving father, it was a blessing that, in the last year of his life, he and his wife had the opportunity to travel to California, USA, to visit their first grandson, Daniel, the newborn son of Gisele, their daughter-in-law, and André.

Since an early age, Leonardo demonstrated a special talent for teaching and sciences. He went to high-school in Cult to Sciences, a traditional school in the city of Campinas, where he was awarded the medal of best student in the scientific course. His classmates used to flock his home to ask him for help in sciences and mathematics. With this strong background, Leonardo went to the Polytechnic School of Engineering of the University of São Paulo (USP), where he graduated in Mechanical Engineering in 1967. He then earned the master's degree in PUC-Rio under the supervision of Prof. Jacques Louis Mercier, in a period when the graduate programs in mechanical engineering in Brazil were still in its infancy, and relied on the contribution of prominent visiting scientists, mainly in the field of fluid mechanics. The topic of his research was the application of intrinsic methods in continuum mechanics. Like some of the brightest students of his generation, he went abroad to continue his studies at the University of Minnesota, USA, under the supervision of Prof. Ephraim M. Sparrow. Leonardo obtained his PhD degree in 1975, 
investigating local mass transfer in corrugated wall ducts and heat exchangers. It is emblematic that his graduate research projects focused on both fundamental problems as well as on applied engineering topics, which make a good characterization of his research output spanning more than 40 years.

Although he obtained his education in famous schools in Brazil and USA, it is the State University of Campinas (UNICAMP) that is inextricably linked to his name. With exception of a relatively short passage at the National University of Brasília (UNB), 1969-1971, he built his entire academic career in the Faculty of Mechanical Engineering at UNICAMP, from 1971 to 2003. During this period, he served in most of the academic administration activities, taught several disciplines at both undergraduate and graduate levels, and carried out a productive research program. Even after retirement, in 2003, Leonardo continued fully active as a collaborator professor, still supervising the work of graduate students and coordinating major projects, most notably the construction of a laboratory building for fuel production research. In the beginning of his career, the course of mechanical engineering at UNICAMP was only in its 5th year. He was, therefore, one of the leading faculty members responsible for it to achieve an international standard of excellence at both undergraduate and graduate levels. For his exceptional contribution to UNICAMP, he received the Zeferino Vaz Academic Recognition Award in 1998.

His research interest covered several topics in the field of thermal sciences, such as thermal radiation, combustion processes, pollution control, fluidized beds, production of fuels, coal gasification, two-phase flow, solar energy, optimization of heat exchangers, etc. His large body of technical publications spanned more than three decades, and is invariably characterized by the highest standard of quality and pristine clarity. His two books, one on thermal radiation and the other on industrial heat transfer, also exemplify his consistent engagement to both hard, difficult fundamental subjects as well as to applied engineering. In a time when the word innovation was not so much in vogue in universities, he registered three patents on the fluidized bed technology. During the period of 1978-1983, Leonardo also worked as a senior engineer at Promon Engenharia SA, developing new technologies for coal gasification as well as for shale combustion in bubbling fluidized beds. He always remained in close cooperation with the industry by offering extension courses to engineers as well as leading applied research projects.

During his career, he taught thousands of undergraduate and graduate students in disciplines such as fluid mechanics, heat transfer, steam generation, thermal radiation, two-phase flow, etc. Very akin to his own personal style, his lectures were always neatly prepared and elegantly delivered. He did not need to speak loud or make theatrical gestures to keep the attention of his students, even the most absentminded ones. Leonardo knew the students by name, and kept a warm class interaction by encouraging questions from the students. As with the best professors, only after diligent hard work, a student could expect to pass his courses. The students who had the good fortune to do their undergraduate or graduate research projects under his advisory, and they were many, found the best work conditions in the laboratory. Leonardo was consistently demanding, always expecting the work to be carried out at the highest level of excellence. There was no compromise on this. When he revised a text, the papers could return all marked in red many times, until the student could produce a truly good material. Although a demanding advisor, he would never lose his patience, the sense of humor or his natural gentleness along the process. When a student was falling way behind schedule, he would only need to arrange his glasses with the fingers, and say: "I'm getting worried about you". Message understood.

Leonardo has also left an enduring legacy as the President of the Brazilian Society of Mechanical Sciences and Engineering (ABCM) during the biennales of 2002-2003 and 2004-2005. Previous to being elected to the presidency of $\mathrm{ABCM}$, he was already an influential member in the society. It could be mentioned his participation in the Organizing Committee of COBEM 1991, or his dedicated service as the Editor-in-Chief of the Journal of the Brazilian Society of Mechanical Sciences and Engineering (JBSMSE) in the period of 1993-1999, helping to transform JBSMSE in one of the best engineering technical journals in Brazil, if not the best one. As the president of ABCM, Leonardo had a deep understanding of the role of the members to strengthen the mechanical engineering and sciences in the country. In his view, the members were at the same time the agents responsible for all the actions of the society, and also the target of the actions. As such, during his office, there was a strong incentive to the active participation of the members in the technical committees as well as in the regional divisions of ABCM. He once said: "ABCM is the great Brazilian community working for the field of sciences and technology. ABCM is the broadening of our humane, technical and scientific horizon. It is the contribution to the common good. ABCM is what we are". It would take much longer to list all the advances of $\mathrm{ABCM}$ in his leadership, but, to highlight at least one of them, it could be mentioned the strengthening and expansion of the ABCM awards for the best undergraduate and graduate works in Brazilian schools, another example of his life-long incentive to excellence in research and education. Leonardo received the ABCM Merit Award in 1999 for his important contributions. 
One cannot speak of Leonardo without saying a word about his deep humanity and spirituality. It was always a joy to talk with him about the "good things of life". He enjoyed literature, cinema and arts in general. But it was music that lived in his heart. He used to say that he could not imagine life without music; it can be said that his life was filled with the most beautiful music. He had a vast collection of classical music albums, ranging from early to modern composers, and covering all possible genres, from sacred cantatas to operas, from chamber music to symphonies. More often, he used to reserve time only for music listening, but sometimes he could be found working on his desk while listening to Monteverdi or Bruckner. Connecting the realms of science and music, he used to say to his students, after the discussion of a scientific paper or thesis, "Music, Maestro!", conveying his confidence that they were ready to conduct the work ahead. Several of his students started enjoying classical music because of him, and this is symbolic of the kind of professor that he was, the one who also teaches the students about beauty: be in the music of Bach, be in the fundaments of thermal sciences.
Leonardo has once been compared to the striving oyster that produces a pearl after being hurt. In fact, when an undesirable impurity contaminates the interior of the oyster, this impurity is involved with layers of nacre to turn it into pearl. In his life, Leonardo endured fierce hardships in more than one occasion. Like the oyster, he covered those hardships with layers of love to turn them into wisdom, which he so generously shared with people who were fortunate to know him. He never lost his unshakable faith in humanity and God. As his wife Lucila has said, Leonardo had a genuine desire to help other people. It could be said the same of his genuine desire to help his academic institution, the entire community of mechanical engineers in Brazil and his country. We will always be thankful to him for this.

For his long-term dedication to the development of engineering practice and education in Brazil, Prof. Leonardo Goldstein Jr. was awarded in 2004 with the National Order of Scientific Merit, in degree of commander. 